\title{
Temperature Response in Hardened Concrete Subjected to Tropical Rainforest Environment
}

\author{
Ernest Ituma Egba \\ Faculty of Civil Engineering \\ Universiti Teknologi Malaysia \\ 81310 Skudai Johor, Malaysia and \\ Ebonyi State University, Abakaliki, \\ PMB 53, Ebonyi State Nigeria \\ letschartup@gmail.com
}

\author{
Mohammad Ismail \\ Faculty of Civil Engineering \\ Universiti Teknologi Malaysia \\ 81310 Skudai Johor, Malaysia \\ mohammad@utm.my
}

\author{
Norhisham Bakhary \\ Faculty of Civil Engineering \\ Universiti Teknologi Malaysia \\ 81310 Skudai Johor, Malaysia and \\ Institute of Noise and Vibration \\ Universiti Teknologi Malaysia \\ norhisham@utm.my
}

\begin{abstract}
The objective of this paper is to characterize the microenvironment temperature response to the natural climate of the tropical rainforest. The peculiar warmth, high humidity, and low pressure nature of the tropical rainforest necessitated the present study. Temperature probes were inserted into concrete specimens subjected to the sheltered and unsheltered environment to measure the micro-environment temperature of the concrete, and study the hysteresis characteristics in relation to the climate temperature. Some mathematical relationships for forecasting the internal temperature of concrete in the tropical rainforest environment were proposed and tested. The proposed relationships were found reliable. It was observed that the microenvironment temperature was lower at the crest, and higher at the trough than the climate environment temperature with a temperature difference of $1-3{ }^{\circ} \mathrm{C}$. Also, temperature response in concrete for the unsheltered micro-environment was 1.85 times faster than the response in the sheltered micro-environment. The findings of the study may be uses to assist the durability assessment of concrete.
\end{abstract}

Keywords-natural climate temperature; Concrete microenvironment temperature; Concrete deterioration; Rainforest tropical climate

\section{INTRODUCTION}

Temperature has been identified as a major factor that influences the performance of concrete as a result of the constant periodic, daily, and seasonal temperature variation. Previous studies have shown various ways that temperature influenced concrete deterioration and service life reduction of concrete structures [1-7]. It has been revealed that the temperature effect on concrete durability was stirred by the concrete micro-environment temperature [3, 8-15]. The submission of previous researchers in [3] showed the relevance of describing the environment parameters in the natural climate and concrete micro-environment based on climate zones. This paper describes the analysis of temperature response in hardened concrete subjected to the natural environment of the tropical rainforest of Johor, Malaysia. The paper also explains the likelihood of concrete deterioration in the tropical rainforest as a result of the influence of the natural climate temperature. Authors in [9] studied the hysteresis characteristics of temperature response of concrete. But the study was pertinent to the subtropical climate that is branded by warm and dry air whereas the tropical rainforest environment is characterized by unusual warmth, high humidity and low pressure. The study aims to assist the description of temperature effect on concrete and efficient concrete durability design.

\section{METHODOLOGY}

\section{A. Concrete Specimen Preparation}

A grade 20 concrete was prepared with ordinary Portland cement, $20 \mathrm{~mm}$ maximum size crushed granite, natural river sand of $5 \mathrm{~mm}$ maximum size, and clean water. Table I shows the composition of the concrete. $100 \mathrm{~mm} \times 150 \mathrm{~mm} \times 150 \mathrm{~mm}$ concrete size specimens with water to cement ratio of 0.6 were prepared, demoulded after 24 hours, and cured in water for 28 days. A temperature probe was inserted into $10 \mathrm{~mm}$ diameter hole, $25 \mathrm{~mm}$ from the surface of the concrete specimen. The $25 \mathrm{~mm}$ was assumed as the approximate reinforcement bar location in reinforced concrete. The specimens were oven dried at the temperature of $105{ }^{\circ} \mathrm{C}$ after the 28 -days water curing, to achieve moisture content free concrete.

TABLE I. CONCRETE COMPOSITION

\begin{tabular}{|c|c|}
\hline Material & Quantity $\mathbf{( K g m}^{-3} \mathbf{)}$ \\
\hline Cement & 350 \\
\hline River sand & 717.6 \\
\hline Crushed granite & 1122.4 \\
\hline Water & 210 \\
\hline
\end{tabular}

\section{B. Exposure Condition}

The specimens that were placed $1500 \mathrm{~mm}$ above the ground level to avoid sorption of ground water were subjected to two exposure conditions, the sheltered, and the unsheltered natural climate exposure conditions. The two exposure conditions were selected to characterize the effect of sunshine and daylight hour on temperature response in concrete.

\section{Data Acquisition and Analysis}

The concrete micro-environment temperature was measured with the XR5-SE data logger at time intervals with 
the use of temperature probe. XR5-SE data logger with a dimension of $124 \mathrm{~mm} \times 56.2 \mathrm{~mm} \times 32.5 \mathrm{~mm}$ has 20 positions screw input terminals and an operating limit of $-40{ }^{\circ} \mathrm{C}$ to $78{ }^{\circ} \mathrm{C}$ and above $5 \%$ relative humidity. The test setup is shown in Figure 1. The natural climate temperature data were collected from the Johor Meteorological service. Statistical data analysis was conducted to describe the extent of likelihood of concrete deterioration in the tropical rainforest environment, as well as the hysteresis characteristics of temperature in concrete.

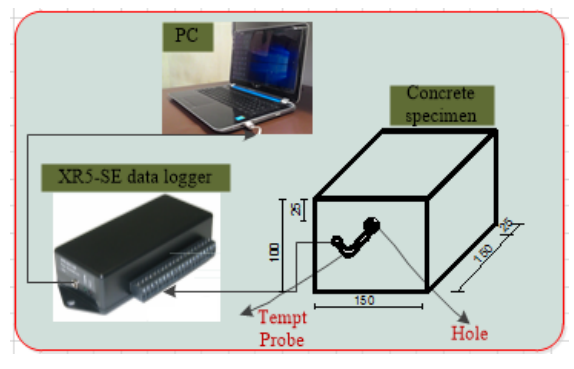

Fig. 1. Test set-up

\section{RESULTS AND DISCUSSION}

\section{A. Natural Climate Temperature}

The natural climate temperature $\mathrm{T}$ values for the month of June, and July are presented in Figures $2 \mathrm{a}$ and $2 \mathrm{~b}$ respectively. The temperature envelope for June 2016 as presented in Figure 2a has the highest and lowest boundaries of $38{ }^{\circ} \mathrm{C}$ and $23{ }^{\circ} \mathrm{C}$ respectively. The June 2016 temperature data was used as the training data set to perform a waveform nonlinear curve fitting analysis to explain the temperature $\mathrm{T}$ and time $\mathrm{t}$ relationship. The function in (1) was deduced.

$$
T=30.253+5.385 \operatorname{Sin}[\pi(t+6.981) / 12.003]
$$

The function explained $80.61 \%$ of the envelope. The function was used to predict the July natural climate temperature data to ascertain its validity. The result as shown in Figure $2 \mathrm{~b}$ indicated that it explained $84.46 \%$ of the July 2016 measured temperature with a mean square error of 2.81 . Figures $2 \mathrm{a}$ and $2 \mathrm{~b}$ revealed that the average temperature within the period of test is $30.48{ }^{\circ} \mathrm{C}$ while the difference of the amplitude crest and trough is $15^{\circ} \mathrm{C}$ with the daily temperaturerise period of about 8.33 hours. The result showed that value of the difference of the amplitude crest and trough differ by $85.2 \%$ compared to the case at Changsha described in [8]. This suggests varying impact of temperature on concrete performance as a result of different degrees of daily temperature fluctuation in the environment. It supports the proposition of researchers that characterization of environmental parameters in the natural climate, and concrete micro-environment should be based on climate zones for adequate design of durable concrete structures $[3,9]$.
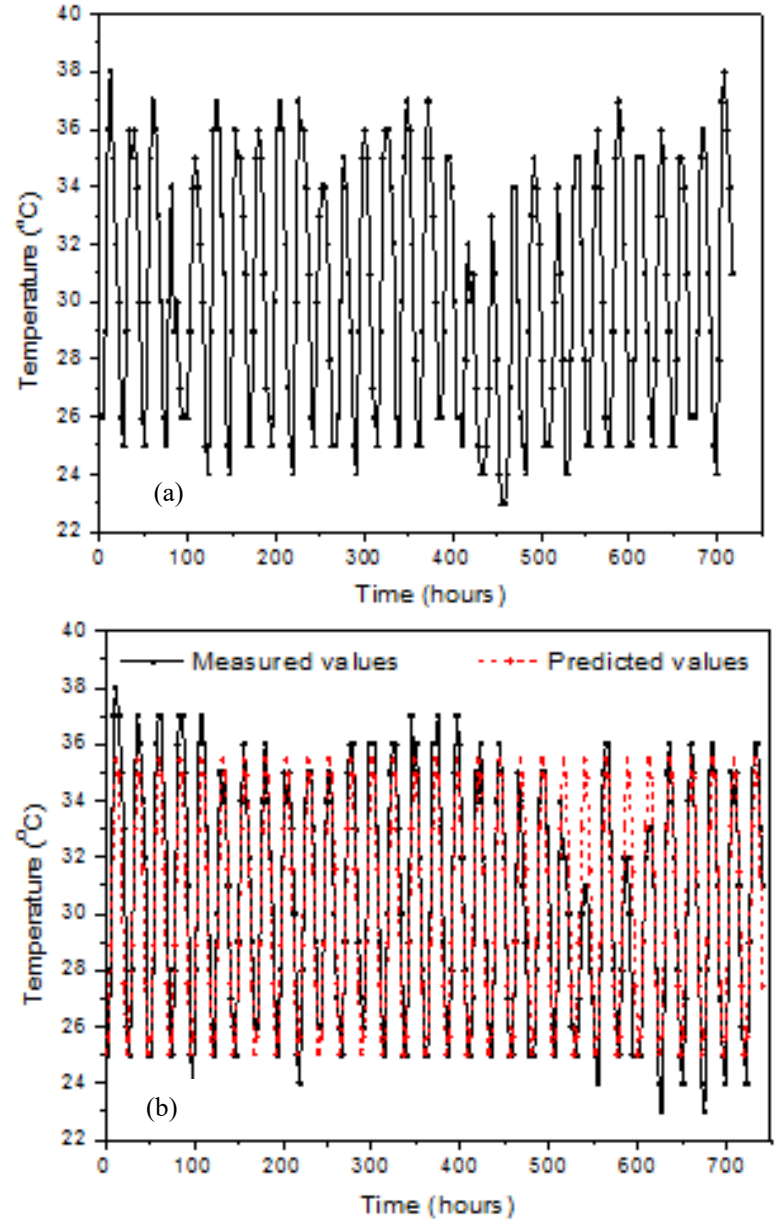

Fig. 2. Natural climate temperature values: (a) month of June 2016, (b) measured and predicted values for the month of July 2016

Also, the cluster analysis chart of the natural climate temperature for the month of June, and July 2016 are presented in Figures 3a, and $3 \mathrm{~b}$ respectively. The chart showed that the natural climate temperature was above $30{ }^{\circ} \mathrm{C}$ for $53.70 \%$ of the studied period. The results indicated that the environment favours significant carbonation, and corrosion of concrete. The deduction was made based on Arrhenius theory and the submission of researchers that concrete deterioration, carbonation and corrosion increase as temperature increases [10-12]. Also, it was opined in [12] that the corrosion of reinforced concrete aggravates from temperature of $20{ }^{\circ} \mathrm{C}$; intensifies as the temperature approaches $40{ }^{\circ} \mathrm{C}$; and decreases above $40{ }^{\circ} \mathrm{C}$. The implication is that the tropical rainforest environment of Johor in Malaysia is absolutely conducive for concrete deterioration and corrosion, since the natural climate temperature envelop falls within $20^{\circ} \mathrm{C}$ to $40^{\circ} \mathrm{C}$. In addition, the environment permits intensified rate of corrosion, since the temperature is above $30^{\circ} \mathrm{C}, 53.70 \%$ of the time.

\section{B. Concrete Micro-Environemnt Temperature}

The daily temperature variations in the climate environment, and the micro-environment for the sheltered and unsheltered concrete specimens are presented in Figure 4. It shows the hysteresis characteristics of temperature response in 
concrete micro-environment. Figures $4 \mathrm{a}$ and $4 \mathrm{~b}$ reveal that the climate environment temperature rises at a faster rate than the micro-environment temperature from the sunrise time to the maximum temperature some hours after the noon time; and falls faster than the micro-environment temperature through the sunset time to the night period. This behaviour could be attributed to the change of transmission medium of temperature, and the coupled effect of heat convection, and conduction. It was observed that the micro-environment temperature was lower at the crest, and higher at the trough than the climate environment temperature with a temperature difference of $1-3{ }^{\circ} \mathrm{C}$. It was deduced from Figure $4 \mathrm{c}$ that temperature response in concrete for the unsheltered microenvironment was faster 1.85 times more than the response in the sheltered micro-environment. Also, Figure 4a shows that it took the micro-environment temperature a minimum of 9 hours to attain the climate environment temperature. The findings agreed with the observation of previous studies that the peak and valley points of micro-environment temperature lag behind the corresponding climate environment temperature with varying values of the range of $1-7^{\circ} \mathrm{C}[8-9,13]$.
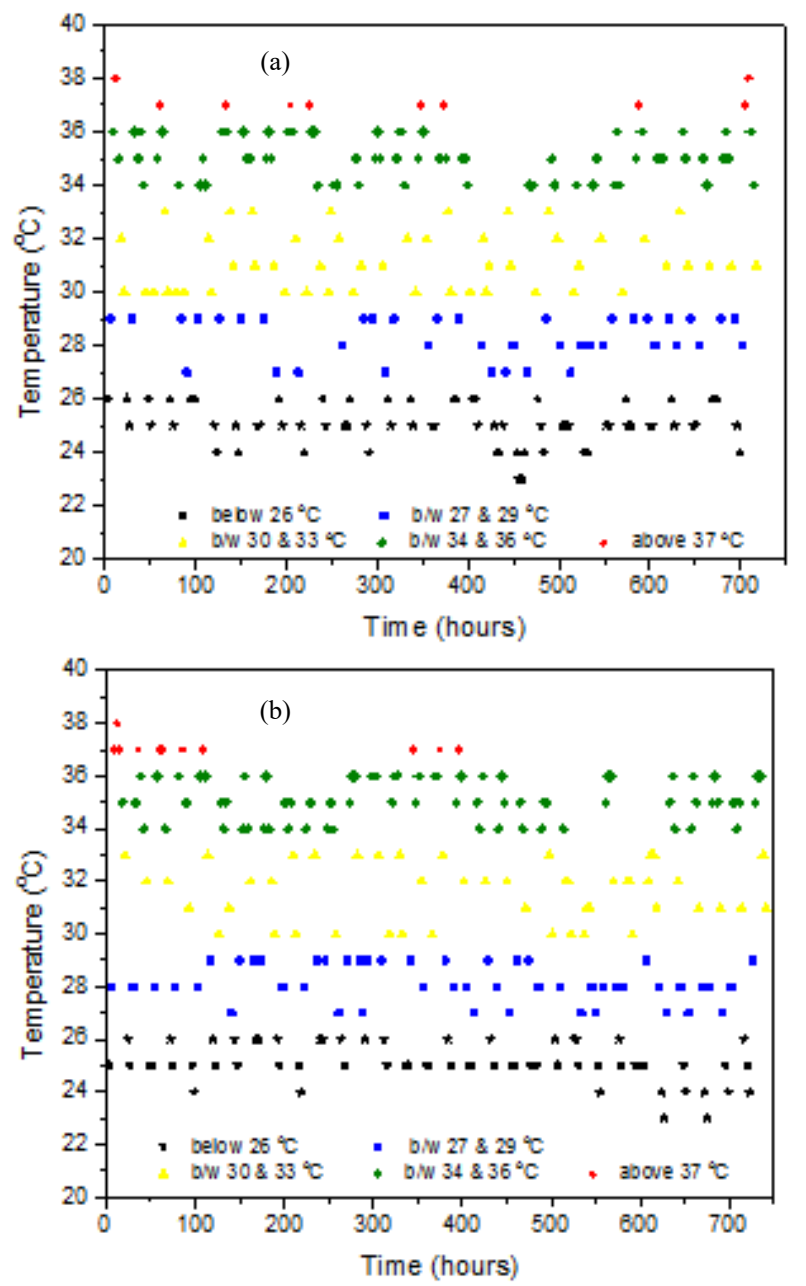

Fig. 3. Cluster analysis of natural climate temperature values: (a) month of June 2016, (b) month of July 2016
The micro-environment temperature data of $1^{\text {st }}-3^{\text {rd }}$ June 2016 was used as the training data to perform a waveform function nonlinear curve fitting analysis to explain the temperature and time relationship. The mathematical expressions for the unsheltered and sheltered microenvironment are presented in (2) and (3) respectively.

$$
\begin{aligned}
& T_{u}=31.481+4.531 \operatorname{Sin}[\pi(t+9.208) / 12.035] \\
& T_{s}=30.943+4.046 \operatorname{Sin}[\pi(t+9.129) / 12.040]
\end{aligned}
$$

where $T_{u}$ and $T_{s}$ denote unsheltered micro-environment temperature, and sheltered micro-environment temperature respectively.

Equations (2) and (3) were used to predict the unsheltered and sheltered micro-environment temperatures respectively, for July 4 - July 6 . The result shown in Figure 5 indicated that (2) explained $83.72 \%$ of the July 2016 measured unsheltered micro-environment temperature with a mean square error of 2.79; while (3) described $85.82 \%$ of the July 2016 measured sheltered micro-environment temperature with a mean square error of 2.00. The result indicated that the expressions were valid for predicting concrete micro-environment temperature.

The daily temperature range for the climate environment is presented in Figure 6. It is indicated that the daily temperature varied most and least at the range of $14{ }^{\circ} \mathrm{C}$ and $6{ }^{\circ} \mathrm{C}$ respectively, with the average range at $10.84{ }^{\circ} \mathrm{C}$. Figure 7 shows the temperature difference for the unsheltered and sheltered micro-environment. Temperature difference described the extent the micro-environment temperature varied from the average daily natural climate temperature. The diagram revealed lesser temperature difference for the unsheltered environment than the sheltered environment. The finding affirmed the claim that temperature response in unsheltered concrete micro-environment is higher than the sheltered micro-environment as a result of sunshine and daylight effects [8-9]. Nevertheless, relationships amongst temperature difference and temperature range are presented in Figures 8(a) and 8(b). The following mathematical expressions were deduced from the relationship by linear regression;

$$
\begin{aligned}
& \Delta T_{u}=-0.024 R-0.009 \\
& \Delta T_{s}=0.041 R-0.190
\end{aligned}
$$

The relationship amongst temperature difference and temperature range for the unsheltered concrete and sheltered concrete are explained in (4) and (5) respectively. The mathematical expressions are useful for predicting concrete micro-environment temperature, providing the daily natural climate temperature range $R$ is known. Be that as it may, the statistics above revealed that the concrete micro-environment temperature was higher than $30{ }^{\circ} \mathrm{C}$ for $80.33 \%$ exposure duration. This value is far from $53.70 \%$ recorded for the natural climate temperature. This suggests that concrete microenvironment temperature is much more responsible for temperature effect on concrete durability. The result is in agreement with earlier studies [8-9, 13-15]. 

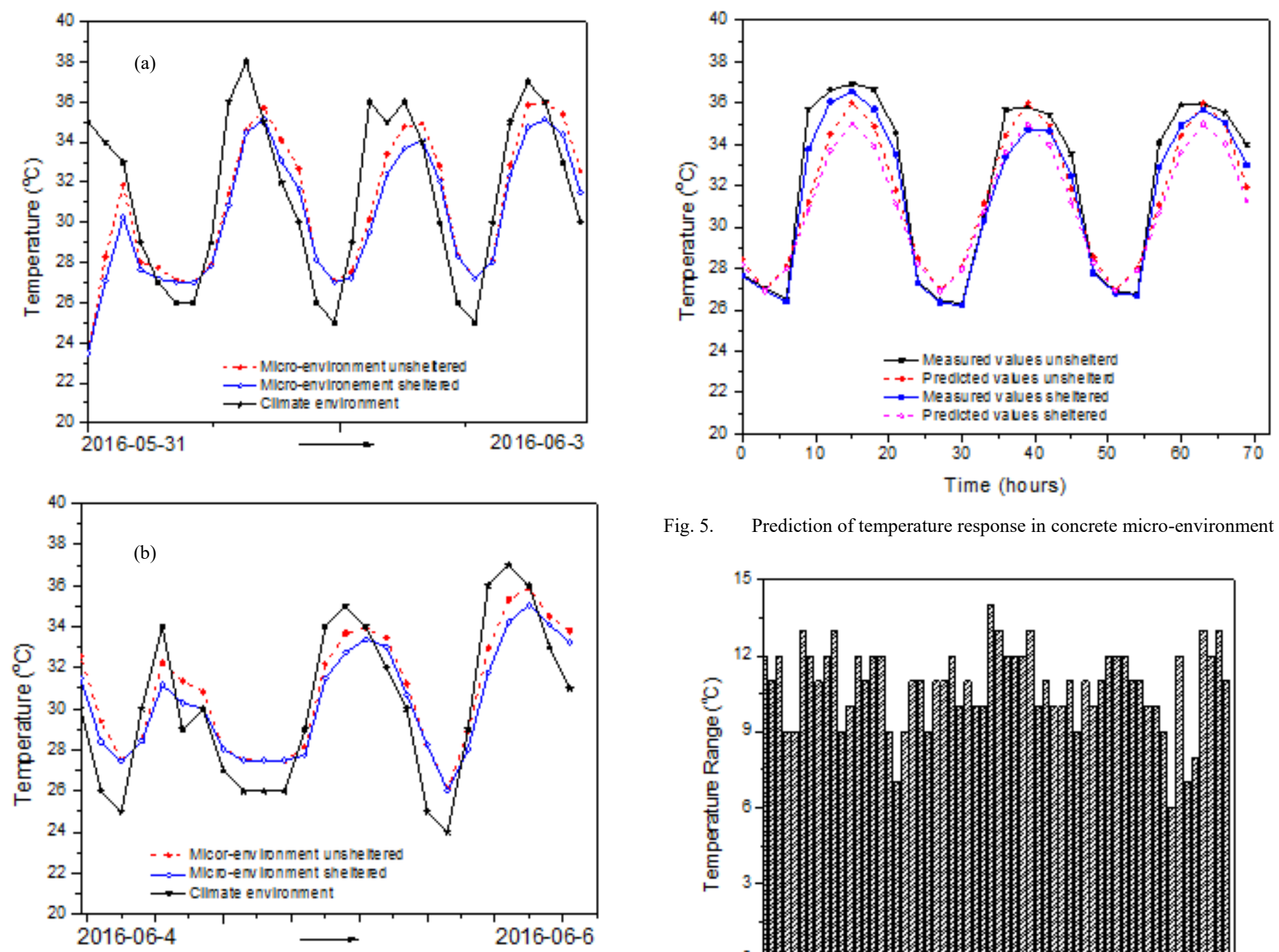

Fig. 5. Prediction of temperature response in concrete micro-environment
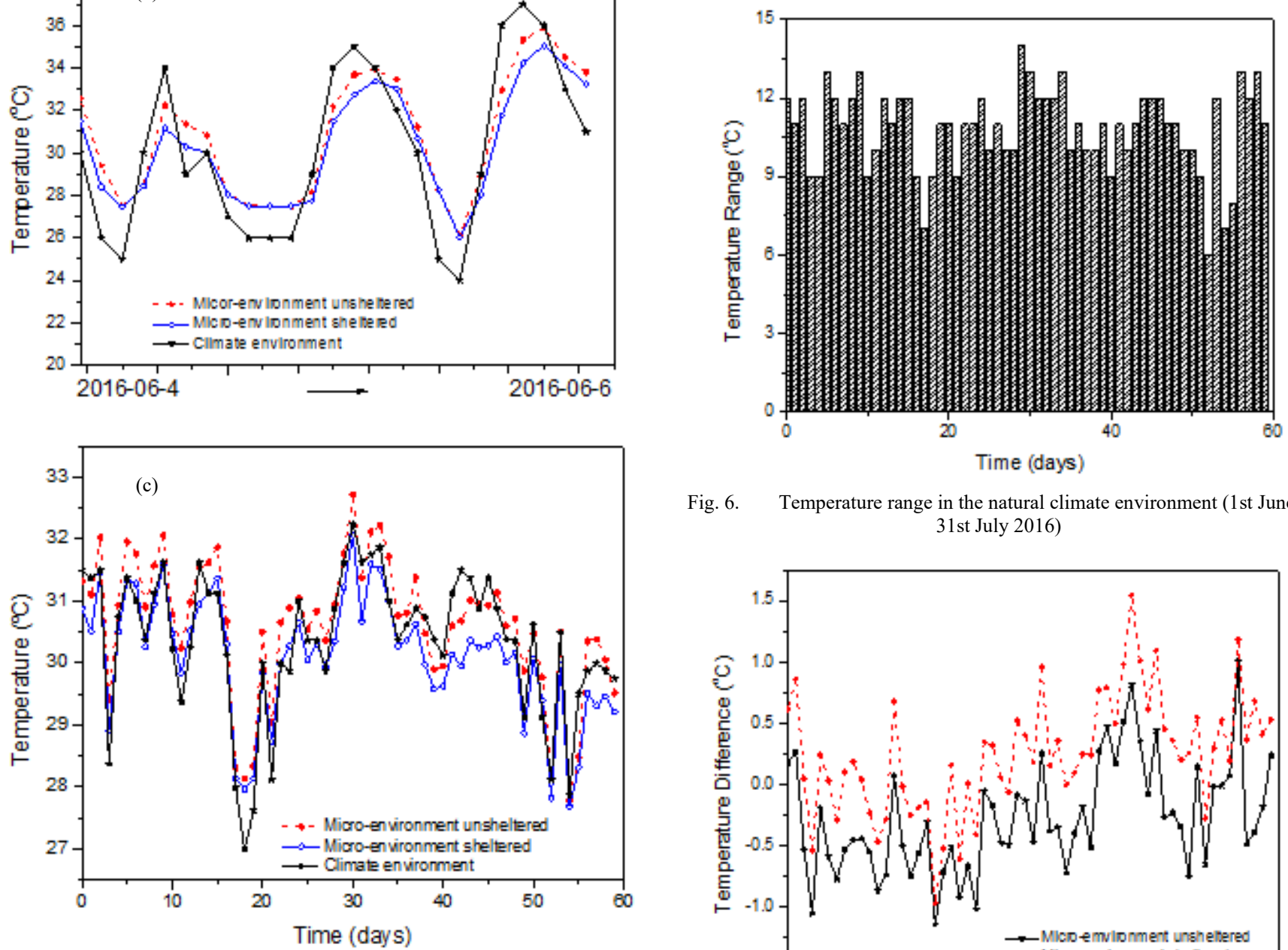

Fig. 6. Temperature range in the natural climate environment (1st June31 st July 2016)

Fig. 4. Hysteresis behaviour of temperature: ture values: (a) $31^{\text {st }}$ May $-3^{\text {rd }}$ June 2016, (b) $4^{\text {th }}$ June $-6^{\text {th }}$ June 2016, (c) daily mean temperature values for June and July 2016

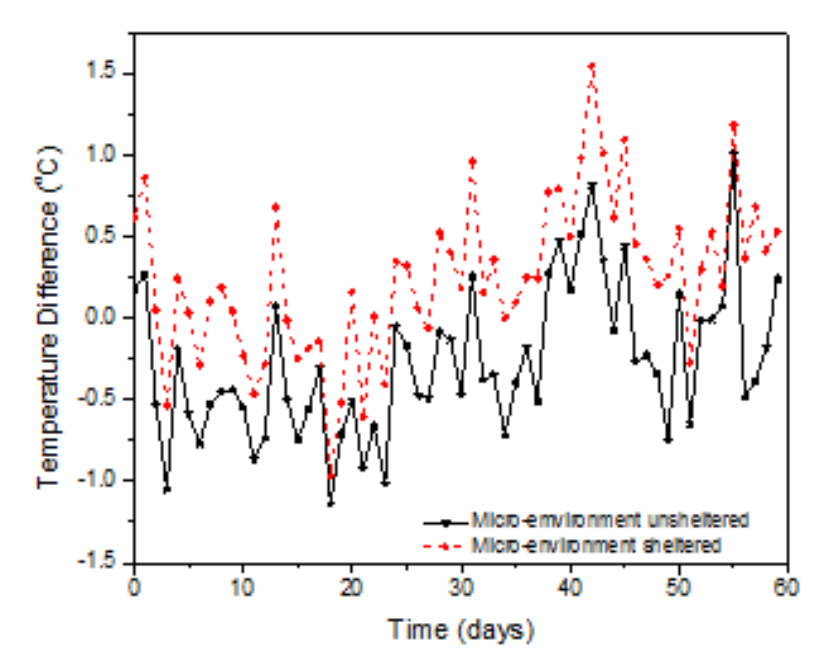

Fig. 7. Temperature difference (1st June - 31 st July 2016) 

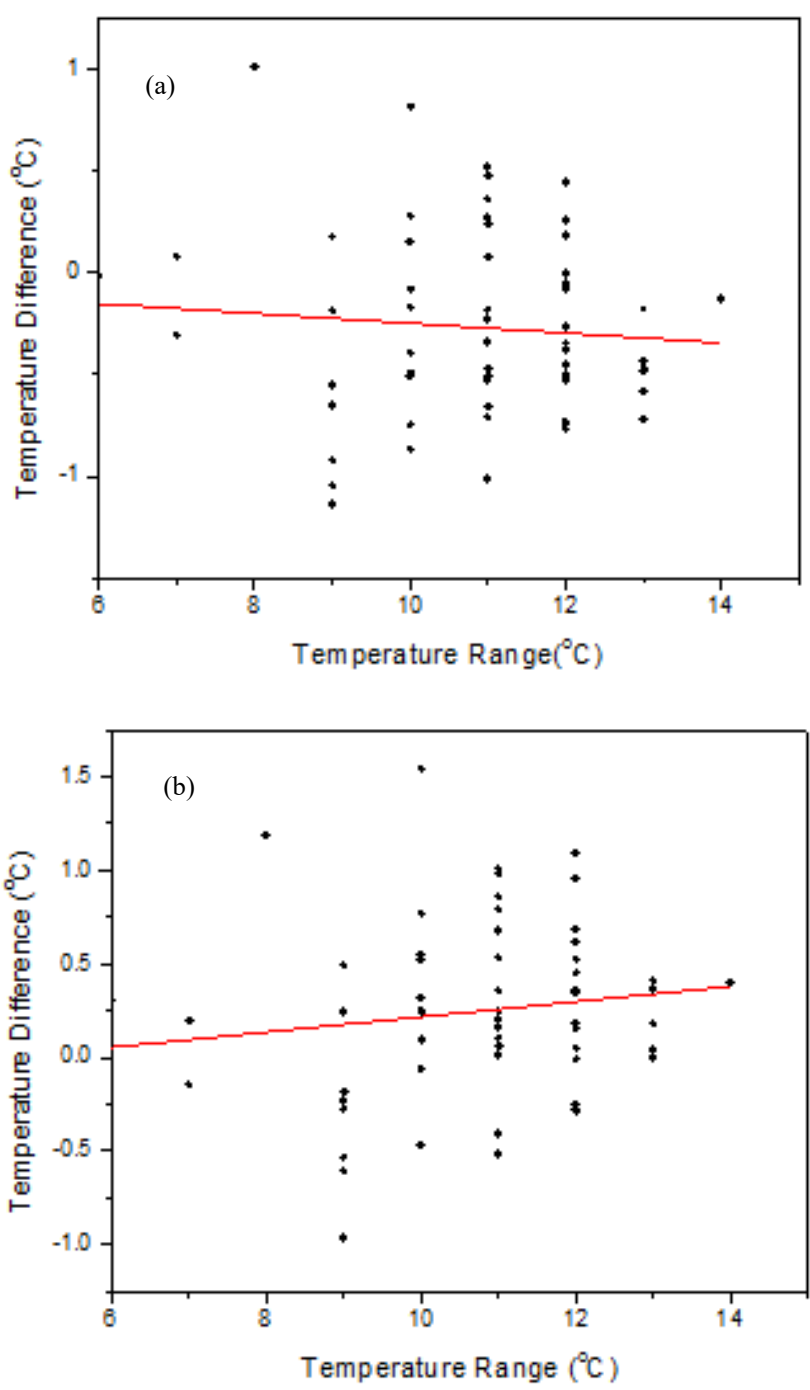

Fig. 8. Relationship between daily temperature range and temperature difference: (a) unsheltered natural environment, (b) sheltered natural environemnt

\section{CONCLUSION}

The present study focused on the analysis of temperature response in concrete. It scrutinised the favourable chances of tropical rainforest environment for concrete deterioration. It also examined the hysteresis behaviour of temperature in concrete. The following deductions were made:

- The natural climate temperature envelop in the tropical rainforest environment of Johor in Malaysia falls within 20 ${ }^{\circ} \mathrm{C}$ to $40{ }^{\circ} \mathrm{C}$, which is absolutely conducive for concrete deterioration,

- The tropical rainforest environment permits intensified rate of corrosion, since the temperature is often above $30{ }^{\circ} \mathrm{C}$, $53.70 \%$ of time.

- The climate environment temperature rises at a faster rate than the micro-environment temperature from the sunrise time to the maximum temperature some hours after the noon time; and falls faster than the micro-environment temperature through the sunset time to the night period; as a result of change of transmission medium of temperature, and the coupled effect of heat convection, and conduction.

- The micro-environment temperature was lower at the crest, and higher at the trough than the climate environment temperature with a temperature difference of 1 to $3{ }^{\circ} \mathrm{C}$.

- Temperature response in concrete for the unsheltered micro-environment was 1.85 times faster than the response in the sheltered micro-environment.

- The daily temperature varies most and least at the range of $14{ }^{\circ} \mathrm{C}$ and $6{ }^{\circ} \mathrm{C}$ respectively, with the average range of about $10.84{ }^{\circ} \mathrm{C}$ at the tropical rainforest environment.

- The temperature response in unsheltered concrete microenvironment is higher than the sheltered micro-environment as a result of sunshine and daylight effects.

\section{ACKNOWLEDGMENT}

The authors gratefully acknowledge the support of Ministry of Higher Education Malaysia for the financial assistance, Grant no: 4F528 for this research; and the financial support received from the Research Management Centre (RMC) Universiti Teknologi Malaysia (UTM), Grant no: 10H06, Faculty of Civil Engineering UTM. Also, appreciated are the support of the Management of Ebonyi State University, Abakaliki, Nigeria; the Management of Tertiary Education Trust Fund (TETFUND), Nigeria; as well as the Technicians, Faculty of Civil Engineering UTM.

\section{REFERENCES}

[1] J. Ortiz, A. Aguado, L. Agullo, T. Garcia, "Influence of environmental temperatures on the concrete compressive strength: simulation of hot and cold weather conditions", Cement and Concrete Research, Vol. 35, pp. 1970-1979, 2005

[2] A. Alhozaimy, R. R. Hussain, R. Al-Zaid, A. Al-Negheimish, "Coupled effect of ambient high relative humidity and varying temperature marine environment on corrosion of reinforced concrete", Construction and Building Materials, Vol. 28, pp. 670-679, 2012

[3] M. N. Haque, H. Al-Khaiat, B. John, "Climate zone - a prelude to designing durable concrete structures in the Arabian Gulf", Building and Environment, Vol. 42, pp. 297-321, 2007

[4] O. B. Hwan, J. S. Yup, "Effect of material and environmental parameters on chloride penetration profile in concrete structures", Cement and Concrete Research, Vol. 37, pp. 47-53, 2007

[5] R. Lyons, M. Ing, A. Simon, "Influence of diurnal and seasonal temperature variations on the detection of corrosion in reinforced concrete by acoustic emission”, Corrosion Science, Vol. 47 pp. 413-433, 2005

[6] T. S. Nguyen, S. Lorente, Carcasses, "Effect of the environment temperature on the chloride diffusion through CEM-1 and CEM-V mortars: An experimental study", Construction and Building Materials, Vol. 23, pp. 795-803, 2009

[7] Y. Xia, H. Hao, G. Zanardo, A. Deeks, "Long term vibration monitoring of an RC slab: temperature and humidity effect", Engineering Structures, Vol. 28, pp. 441-452, 2006

[8] P. Liu, Z. Yu, F. Guo, Y. Chen, P. Sun, "Temperature response in concrete under natural environment", Construction and Building Materials, Vol. 98, pp. 713-721, 2015 
[9] Y. Yuan, J. Jiang, "Climate load model - climate action spectrum for predicting durability of concrete structure", Construction and Building Materials, Vol. 29, pp. 291-298, 2012

[10] A. Dousti, R. Rashetnia, B. Ahmadi, M. Shekarchi, "Influence of exposure temperature on chloride diffusion in concretes incorporating silica fume or natural zeolite", Construct Building Materials, Vol. 49, 393-399, 2013

[11] A. Alhozaimy, R. R. Hussain, R. Al-Zaid, A. Al-Negheimish, "Coupled effect of ambient high relative humidity and varying temperature marine environment on corrosion of reinforced concrete", Construct Building Materials, Vol. 28, pp. 670-679, 2012

[12] V. Zivica, L. Krajci, L. Bagel, M. Vargova, "Significance of the ambient temperature and the steel material in the process of concrete reinforcement corrosion”, Construct Building Materials, Vol. 11, No. 2, pp. 99-103, 1997

[13] Y. Yuan, J. Jiang, "Prediction of temperature response in concrete in a natural climate environment", Construction and Building Materials, Vol. 25, pp. 3159-3167, 2011

[14] C. Y. Chang, S. S. Hung, "Implementing RFIC and sensor technology to measure temperature and humidity inside concrete structures", Construction and Building Materials, Vol. 26, pp. 628-637, 2012

[15] J. Jiang, Y. Yuan, "Prediction model for the time-varying corrosion rate of rebar based on micro-environment in concrete", Construction and Building Materials, Vol. 35, pp. 625-632, 2012 